Check for updates

Cite this: RSC Adv., 2019, 9, 11054

Received 25th June 2018

Accepted 3rd April 2019

DOI: 10.1039/c8ra05421e

rsc.li/rsc-advances

\section{Effects of spermine on liver barrier function, amino
acid transporters, immune status, and apoptosis in \\ Effects of spermine on liver barrier function, amino
acid transporters, immune status, and apoptosis in piglets $\uparrow$}

\author{
Guangmang Liu, (D)*ab Jie Zheng, ${ }^{\text {ab }}$ Wei Cao, ${ }^{\text {ab }}$ Xianjian Wu, ${ }^{\text {ab }}$ Gang Jia, ${ }^{\text {ab Hua Zhao, }}$, \\ Xiaoling Chen, ${ }^{\mathrm{ab}}$ Caimei $\mathrm{Wu}^{\mathrm{ab}}$ and Jing Wang ${ }^{\mathrm{C}}$
}

\begin{abstract}
This study investigated the effects of spermine supplementation and its extended duration on amino acid transporters, immune status, barrier function, and apoptosis in the liver. Eighty piglets were randomly assigned to a group receiving either a diet supplemented with spermine $\left(0.4 \mathrm{mmol} \mathrm{kg} \mathrm{k}^{-1}\right.$ of body weight) or a restricted nutrient intake supplemented with saline in pairs for 7 h, 3 days, 6 days, and 9 days. Regardless of treatment time, spermine increased the levels of amino acid transporters, immunoglobulin M, antimicrobial peptides, cellular immune components, anti-inflammatory cytokines, mammalian target of rapamycin, ribosomal protein S6 kinase 1, signal transducer and activator of transcription 2 and 3, Janus kinase 2, zonula occludens 1 and 2, occluding, claudin-1, claudin-2, claudin16 and $\mathrm{Bcl}-2$ mRNA levels, whereas it decreased the levels of pro-inflammatory cytokines, inducible nitric oxide synthase, nuclear factor-kappa B P65, eukaryotic IF4E-binding protein 1, myosin light chain kinase, Bax, and caspase-3 mRNA in the liver $(P<0.05)$. These effects were also found in cases of prolonged spermine intake $(P<0.05)$. Spermine can decrease pro-inflammatory cytokines and caspase3 levels. In conclusion, spermine may promote barrier function and improve amino acid transport, and can increase immune status and inhibit apoptosis in the liver.
\end{abstract}

\section{Introduction}

Spermine, which is the most strongly basic polyamine, participates in regulating transcription and translation; modulating kinase activities; maintaining the structure and stability of cellular macromolecules; controlling cell proliferation, differentiation, and apoptosis; and protecting the immune status. ${ }^{1}$ The liver is the main metabolic and immune organ in the body. Amino acid metabolism depends on amino acid transporters, and spermine increases the transcription of amino acid transporter families in the spleen and thymus, such as the solute carrier 1 (SLC1) and SLC7 families. ${ }^{2}$ However, limited information is available on the effect of spermine and its duration on amino acid transporter transcription in the livers of pigs.

Innate immune status relies on humoral (e.g., antimicrobial peptide and IgM) and cellular immune components (e.g., as lymphocyte). ${ }^{3}$ Arginine (the precursor of spermine) increased

Institute of Animal Nutrition, Sichuan Agricultural University, Chengdu 611130, Sichuan, China. E-mail: liugm@sicau.edu.cn; Tel: +86-28-86290976

${ }^{b}$ Key Laboratory for Animal Disease-Resistance Nutrition of China Ministry of Education, Chengdu 611130, Sichuan, China

${ }^{c}$ Maize Research Institute, Sichuan Agricultural University, Chengdu 611130, Sichuan, China

† Electronic supplementary information (ESI) available. See DOI: 10.1039/c8ra05421e the mRNA levels of antimicrobial peptides in pigs. ${ }^{4}$ In addition, L-arginine supplementation up-regulated the IgM transcription in the serum of piglets. ${ }^{5}$ Spermine improved the IgM mRNA levels in the thymus and spleen of piglets. ${ }^{6}$ These findings suggested that spermine might improve the humoral immunity in pigs. However, the effects of spermine supplementation and its duration on the humoral immunity in the liver have yet to be clarified. Moreover, spermine improved the transcription of cellular immune components in the thymus and spleen of piglets. ${ }^{6}$ However, the improvement effect of spermine and its duration on cellular immunity remains unclear.

Inflammatory response is involved in innate immune response. $^{7}$ Spermine supplementation reduced proinflammatory cytokines, including interleukin (IL)-2, IL- $\beta$, and interferon (IFN)- $\gamma$ in the serum. ${ }^{6}$ Spermine supplementation increased the mRNA levels of anti-inflammatory cytokines and decreased those of pro-inflammatory cytokines in the thymus and the spleen. ${ }^{6}$ However, the effect of spermine and its duration on the transcription of inflammatory cytokines in the liver remain unclear. The regulation of inflammatory response is related to the transcription of signaling pathway molecules. Spermine supplementation increased the transcription of several immune-related signaling pathway molecules in the thymus and the spleen, including mammalian target of rapamycin (mTOR), nuclear factor-kappa B (NF-кB), signal transducer and activator of transcription (STATs), and Janus kinase 
(JAK). ${ }^{6}$ However, the exact effects of spermine and its duration on these signaling pathway molecules in the liver are unknown.

Immunity depends on structural integrity, which is associated with the tight junction proteins of organs. ${ }^{\mathbf{8} 9}$ Arginine limited the decrease in zonula occludens ( $\mathrm{ZO})-1$ and occludin expression in methotrexate-treated Caco- 2 cells. ${ }^{10}$ In addition, arginine up-regulated the ZO-1, occludin, and claudin-3 mRNA levels in fish with $\mathrm{Cu}$-induced epithelial barrier function damage. ${ }^{11}$ Polyamine depletion decreased the ZO-1, ZO-2, claudin-2, claudin-3, and occludin protein levels in IEC-6 cells. $^{12}$ These observations revealed that spermine might upregulate the transcription of tight junction proteins in the liver of pigs, and this phenomenon deserves further investigation. Junction proteins are involved in maintaining structural integrity. Structural integrity has been ascribed to cellular membrane integrity, which can be destructed by oxidative damage and cell apoptosis. ${ }^{13}$ Our previous study reported that spermine improved the antioxidant status by increasing the gene expression of antioxidant enzymes and antioxidant-related signaling molecules in the liver of weaning piglets. ${ }^{14}$ Similarly, spermine increased the antioxidant capacity in the liver of rats under oxidative stress. ${ }^{15}$ These reports suggested that spermine protected the cellular membrane integrity by increasing antioxidant status. However, the protective effect of spermine on the cellular membrane integrity by suppressing cell apoptosis is unclear. The present study is part of a large research project investigating the various effects of spermine administration on the intestinal development and antioxidant status of liver. ${ }^{\mathbf{1 4 , 1 6}}$ This experiment aimed to investigate the effects of spermine supplementation and its duration extension on liver barrier function, amino acid transporters, immune status, and apoptosis in piglets.

\section{Materials and methods}

\section{Animal experiments and sample collection}

All animal procedures were performed in accordance with the Guidelines for Care and Use of Laboratory Animals of National Research Council and approved by the Animal Ethics Committee of Sichuan Agricultural University. The detailed experimental design and procedures were described by our previous study. ${ }^{6}$ The basic formula diet (Table $\mathrm{S} 1 \dagger$ ) was provided by mixing $1 \mathrm{~kg}$ formula milk (dry matter 87.5\%) and $4 \mathrm{l}$ drinking water. A total of 80 piglets were randomly assigned into eight groups ( $n=10$ per group). Four groups comprised sperminesupplemented piglets that received free access to milk-based spermine ( $0.4 \mathrm{mmol}$ per $\mathrm{kg}$ body weight) once a day for $7 \mathrm{~h}, 3$ days, 6 days, and 9 days (Groups SP-7 h, SP-3 d, SP-6 d, and SP-9 $\mathrm{d}$, respectively). Four matched control groups received the same amount of milk-based diet given to the spermine-administered piglets with normal saline once a day for 7 hours, 3 days, 6 days, and 9 days (Groups Con-7 h, Con-3 d, Con-6 d, and Con-9 d, respectively). Spermine (S3256) was purchased from Sigma Chemical Co. (St. Louis, MO, USA) and the dosage was selected based on Cheng et al. ${ }^{17}$ The piglets had free access to drinking water and obtained corresponding basic formula milk each meal. The ambient temperature and relative humidity were maintained at approximately $30{ }^{\circ} \mathrm{C}$ and 50-60\%, respectively.

Piglets were sacrificed at the end of $7 \mathrm{~h}, 3 \mathrm{~d}, 6 \mathrm{~d}$ and 9 $\mathrm{d}$ experimental feeding time for the liver sample collection (at this time, the piglets were 12, 15, 18 and 21 days old, respectively). The liver samples were collected and stored at $-80^{\circ} \mathrm{C}$ for quantification real-time PCR (qRT-PCR) analysis.

\section{Total RNA extraction and qRT-PCR determination of liver}

The total RNA extraction and qRT-PCR determination of liver was performed as described by Cao et al. ${ }^{2}$ Briefly, the total RNA of liver was extracted by TRIzol Regent (Takara, Dalian, China) followed the instruction of manufacturer. Aliquots of $4 \mu \mathrm{g}$ of RNA were received $1.0 \%$ agarose gel electrophoresis to measure their integrity and quality. After that, cDNA was synthesised using $1 \mu \mathrm{g}$ total RNA sample followed with the protocol of a PrimeScript ${ }^{\mathrm{TM}}$ RT reagent kit with gDNA Eraser (Takara, Dalian, China). All specific primers were designed based on the published sequences of pigs (Table S2 $\dagger$ ). The quantification RTPCR of genes was performed by a RT-PCR system (ABI 7900HT, Applied Biosystem, USA) with SYBR® Green I PCR regent kit. The reaction mixture $(8 \mu \mathrm{l})$ consisted of $0.8 \mu \mathrm{l}$ forward reverse primer $(10 \mu \mathrm{M}), 4 \mu \mathrm{l}$ SYBR Premix Ex Taq II with ROX Reference

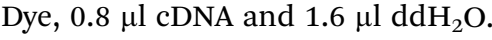

\section{Statistical analysis}

All data were performed by two-way ANOVA using the general linear model procedure of SPSS 22.0 (SPSS Inc., Chicago, IL, USA). Shapiro-Wilk's $W$-test and Levene's test were used to determine the normality and homogeneity, respectively. The main effects in the current study included spermine level ( 0 or $0.4 \mathrm{mmol}$ per $\mathrm{kg}$ body weight), treatment time ( $7 \mathrm{~h}, 3 \mathrm{~d}, 6 \mathrm{~d}$ and 9 d) and their interaction. If a significant treatment effect of their interaction was observed, the significance between the treatment differences was identified separately by Tukey's multiplerange test. Correlation analysis was achieved by Pearson correlation analysis. All results were expressed as mean \pm SEM and statistical differences were regarded as significant at $P<0.05$.

\section{Results}

\section{The weight of livers}

The data of the weight of livers was represented in Table 1, regardless of treatment time, spermine significantly increased the weight of liver $(P<0.05)$.

\section{Amino acid transporters}

As shown in Table 2, regardless of treatment time, spermine significantly increased the mRNA level of SLC7A7 $(P<0.05)$. Moreover, spermine also increased the mRNA level of SLC1A1 (Groups SP-3 d vs. Con-3 d, SP-6 d vs. Con-6 d, SP-9 d vs. Con-9 d), SLC15A1 (Groups SP-6 d vs. Con-6 d), SLC7A9 (Groups SP-3 d vs. Con-3 d, SP-6 d vs. Con-6 d, SP-9 d vs. Con-9 d) in the liver $(P<0.05)$. When the spermine treatment time was prolonged, the mRNA levels SLC1A1, SCL1A5, SLC7A1, SLC7A9 gradually increased $(P<0.05)$. 
Table 1 Effect of spermine supplementation on the weight of liver in piglets ${ }^{a}$

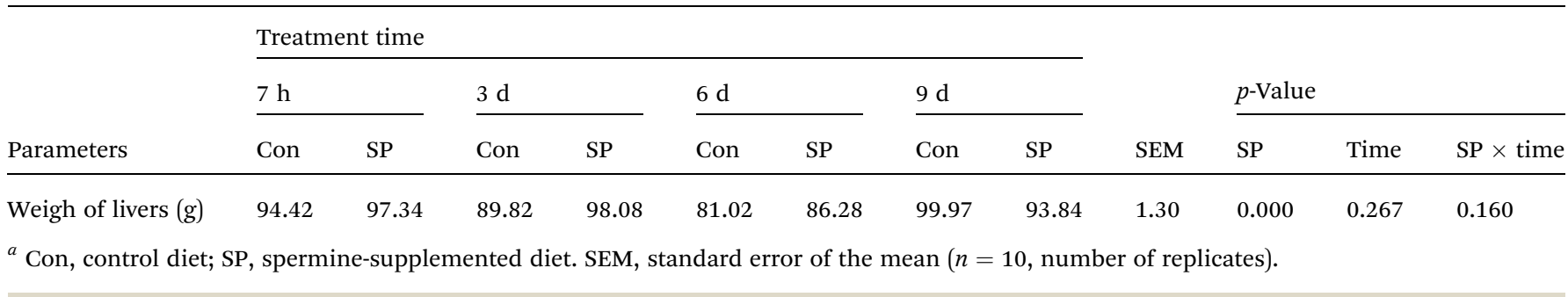

\section{Immune-related parameter}

The results of immune-related parameters were revealed in Tables 3 and 4 . Regardless of treatment time, spermine increased the mRNA level of $\beta$-defensin 1 , but decreased the mRNA level of iNOS $(P<0.05)$. Spermine increased the mRNA levels of IgM (Groups SP-3 d vs. Con-3 d), LEAP2 (Groups SP-6 d vs. Con-6 d), hepcidin (Groups SP-7 h vs. Con-7 h, SP-3 d vs. Con-3 d, SP-6 d vs. Con-6 d), CD8 (Groups SP-3 d vs. Con-3 d), CD18 (Groups SP-7 h vs. Con-7 h, SP-3 d vs. Con-3 d, SP-9 d vs. Con-9 d), TGF- $\beta 1$ (Groups SP-7 h vs. Con-7 h, SP-3 d vs. Con-3 d, SP-9 d vs. Con-9 d), but decreased TNF- $\alpha$ (Groups SP-3 d vs. Con$3 \mathrm{~d}$, SP-6 d vs. Con-6 d) and IL-8 (Groups SP-3 d vs. Con-3 d), TNF- $\alpha$ (Groups SP-3 d vs. Con-3 d, SP-6 d vs. Con-6 d) and IL-8 (Groups SP-3 d vs. Con-3 d) in the liver $(P<0.05)$. Spermine significantly reduced levels of the TNF- $\alpha$ and IL-1 $\beta$ (the main effect) in the liver $(P<0.05)$. When the spermine treatment time was prolonged, the TGF- $\beta 1$ and IgM mRNA level gradually increased and then decreased thereafter $(P<0.05)$.

\section{Immune-related signaling molecules gene expression}

The gene expression of immune-related signaling molecules gene expression was presented in Fig. 1. Spermine significantly up-regulated the mTOR mRNA level (Groups SP-6 d vs. Con-6 d, SP-9 d vs. Con-9 d) and increased the S6K1 mRNA level (Groups SP-7 h vs. Con-7 h, SP-9 d vs. Con-9 d), STAT3 mRNA level (Groups SP-3 d vs. Con-3 d), but decreased NF-кB P65 mRNA level (Groups SP-9 d vs. Con-9 d) in the liver $(P<0.05)$. When the spermine supplementation time was prolonged, the mRNA levels of mTOR and JAK2 increased and then decreased thereafter $(P<0.05)$.

\section{Tight junction proteins gene expression}

The results of tight junction proteins mRNA levels were shown in Table 5. Regardless of treatment time, spermine increased the occludin mRNA level $(P<0.05)$. Spermine significantly increased the mRNA levels of claudin-1 (Groups SP-3 $\mathrm{d} v$ s. Con-3 d), claudin-2 (Groups SP-7 h vs. Con-7 h, SP-6 d vs. Con-6 d), claudin-16 (Groups SP-7 h vs. Con-7 h, SP-3 d vs. Con-3 d, SP-6 d vs. Con-6 d), ZO-1 (Groups SP-3 d vs. Con-3 d), but decreased MLCK mRNA level (Groups SP-3 d vs. Con-3 d) in the liver $(P<0.05)$. When spermine supplementation time was prolonged, claudin 15, claudin16 mRNA level was decreased and the lowest value was observed in $9 \mathrm{~d}$ spermine group $(P<$ 0.05).

\section{Apoptosis-related molecules gene expression}

The results of apoptosis-related molecules were presented in Fig. 2 and Table 4. Regardless of treatment time, spermine significantly decreased the Bax mRNA level (the main effect) in the liver $(P<0.05)$. Spermine increased Bcl-2 mRNA level (Groups SP-6 d vs. Con-6 d, SP-9 d vs. Con-9 d) but decreased caspase-3 level (Groups SP-6 d vs. Con-6 d) in the liver $(P<0.05)$. The Bcl-2 mRNA level gradually increased with the duration of spermine supplementation of up to 6 days and then decreased thereafter. The caspase- 3 mRNA level gradually decreased with prolonged spermine supplementation of up to 6 days and then

Table 2 Effect of spermine supplementation on the amino acids transporters mRNA levels in the liver of piglets ${ }^{a}$

\begin{tabular}{|c|c|c|c|c|c|c|c|c|c|c|c|c|}
\hline \multirow[b]{3}{*}{ Parameters } & \multicolumn{8}{|c|}{ Treatment time } & \multirow[b]{3}{*}{ SEM } & \multirow{2}{*}{\multicolumn{3}{|c|}{$p$-Value }} \\
\hline & \multicolumn{2}{|l|}{$7 \mathrm{~h}$} & \multicolumn{2}{|l|}{$3 \mathrm{~d}$} & \multicolumn{2}{|l|}{$6 \mathrm{~d}$} & \multicolumn{2}{|l|}{$9 \mathrm{~d}$} & & & & \\
\hline & Con & SP & Con & SP & Con & SP & Con & SP & & SP & Time & $\mathrm{SP} \times$ time \\
\hline SLC1A1 & $1.00^{\mathrm{a}}$ & $1.68^{\mathrm{a}}$ & $1.68^{\mathrm{a}}$ & $2.93^{\mathrm{b}}$ & $1.70^{\mathrm{a}}$ & $3.90^{\mathrm{b}}$ & $1.41^{\mathrm{a}}$ & $11.37^{\mathrm{b}}$ & 0.51 & 0.000 & 0.000 & 0.000 \\
\hline SLC1A5 & $1.00^{\mathrm{a}}$ & $1.02^{\mathrm{a}}$ & $1.93^{\mathrm{ab}}$ & $2.83^{\mathrm{b}}$ & $1.90^{\mathrm{ab}}$ & $2.33^{\mathrm{ab}}$ & $1.98^{\mathrm{ab}}$ & $4.45^{\mathrm{b}}$ & 0.18 & 0.000 & 0.000 & 0.034 \\
\hline SLC7A1 & $1.00^{\mathrm{a}}$ & $1.14^{\mathrm{a}}$ & $1.89^{\mathrm{ab}}$ & $4.07^{\mathrm{b}}$ & $1.81^{\mathrm{ab}}$ & $5.51^{\mathrm{b}}$ & $1.73^{\mathrm{ab}}$ & $3.54^{\mathrm{b}}$ & 0.24 & 0.000 & 0.000 & 0.000 \\
\hline SLC7A7 & 1.00 & 1.21 & 1.41 & 2.39 & 1.72 & 2.85 & 1.50 & 3.35 & 0.14 & 0.000 & 0.000 & 0.181 \\
\hline SLC7A9 & $1.00^{\mathrm{ab}}$ & $1.07^{\mathrm{ab}}$ & $0.78^{\mathrm{a}}$ & $2.36^{\mathrm{cd}}$ & $1.80^{\mathrm{c}}$ & $4.04^{\mathrm{de}}$ & $1.72^{\mathrm{bc}}$ & $5.32^{\mathrm{e}}$ & 0.22 & 0.000 & 0.000 & 0.000 \\
\hline SLC6A19 & 1.00 & 0.90 & 0.98 & 1.12 & 0.87 & 0.93 & 0.93 & 0.94 & 0.03 & 0.616 & 0.706 & 0.661 \\
\hline SLC15A1 & $1.00^{\mathrm{a}}$ & $1.64^{\mathrm{ab}}$ & $1.82^{\mathrm{b}}$ & $2.30^{\mathrm{b}}$ & $1.92^{\mathrm{b}}$ & $5.69^{c}$ & $1.86^{\mathrm{b}}$ & $3.60^{\mathrm{b}}$ & 0.22 & 0.000 & 0.000 & 0.000 \\
\hline
\end{tabular}

${ }^{a}$ Con, control diet; SP, spermine-supplemented diet; SLC (7A1, 7A7, 7A9, 5A1, 6A19, 15A1), solute carrier family (7A1, 7A7, 7A9, 5A1, 6A19, 15A1). SEM, standard error of the mean $\left(n=6\right.$, number of replicates) ${ }^{\mathrm{a}-\mathrm{e}}$ Mean in the same row with different superscripts are significantly different at $P<$ 0.05 . 
Table 3 Effects of spermine supplementation on gene expressions of immune parameters in the liver of piglets ${ }^{a}$

\begin{tabular}{|c|c|c|c|c|c|c|c|c|c|c|c|c|}
\hline Parameters & \multicolumn{8}{|c|}{ Treatment time } & SEM & \multicolumn{3}{|c|}{$p$-Value } \\
\hline TNF- $\alpha$ & $1.00^{\mathrm{ab}}$ & $0.82^{\mathrm{a}}$ & $1.85^{\mathrm{c}}$ & $1.18^{\mathrm{b}}$ & $1.63^{\mathrm{c}}$ & $0.91^{\mathrm{ab}}$ & $0.99^{\mathrm{ab}}$ & $0.87^{\mathrm{ab}}$ & 0.06 & 0.000 & 0.000 & 0.000 \\
\hline IL-6 & 1.00 & 0.92 & 0.61 & 0.77 & 0.41 & 0.48 & 0.30 & 0.17 & 0.04 & 0.947 & 0.000 & 0.066 \\
\hline IL-12 & $1.00^{\mathrm{b}}$ & $0.82^{\mathrm{ab}}$ & $0.92^{\mathrm{ab}}$ & $0.92^{\mathrm{ab}}$ & $0.65^{\mathrm{a}}$ & $0.89^{\mathrm{ab}}$ & $1.11^{\mathrm{b}}$ & $1.11^{\mathrm{b}}$ & 0.03 & 0.766 & 0.000 & 0.046 \\
\hline TGF- $\beta 1$ & $1.00^{\mathrm{ab}}$ & $1.57^{\mathrm{d}}$ & $1.50^{\mathrm{cd}}$ & $2.04^{\mathrm{e}}$ & $1.47^{\mathrm{cd}}$ & $1.21^{\mathrm{bc}}$ & $1.12^{\mathrm{b}}$ & $0.71^{\mathrm{a}}$ & 0.06 & 0.017 & 0.000 & 0.000 \\
\hline IFN- $\gamma$ & $1.00^{\mathrm{ab}}$ & $0.69^{\mathrm{a}}$ & $1.02^{\mathrm{ab}}$ & $1.06^{\mathrm{ab}}$ & $1.90^{\mathrm{c}}$ & $1.30^{\mathrm{abc}}$ & $2.19^{\mathrm{c}}$ & $1.68^{\mathrm{bc}}$ & 0.08 & 0.000 & 0.000 & 0.026 \\
\hline $\operatorname{IgM}$ & $1.00^{\mathrm{a}}$ & $1.17^{\mathrm{a}}$ & $1.21^{\mathrm{a}}$ & $2.33^{\mathrm{b}}$ & $2.07^{\mathrm{b}}$ & $2.22^{\mathrm{b}}$ & $1.30^{\mathrm{a}}$ & $1.34^{\mathrm{a}}$ & 0.08 & 0.000 & 0.000 & 0.000 \\
\hline CD8 & $1.00^{\mathrm{a}}$ & $1.45^{\mathrm{ab}}$ & $2.18^{\mathrm{c}}$ & $3.49^{\mathrm{d}}$ & $2.1^{\mathrm{bc}}$ & $2.15^{\mathrm{c}}$ & $2.14^{\mathrm{c}}$ & $1.69^{\mathrm{abc}}$ & 0.11 & 0.003 & 0.000 & 0.000 \\
\hline LFA-1 & $1.00^{\mathrm{b}}$ & $1.42^{\mathrm{d}}$ & $1.33^{\mathrm{cd}}$ & $2.19^{\mathrm{e}}$ & $1.12^{\mathrm{bc}}$ & $1.02^{\mathrm{b}}$ & $0.85^{\mathrm{b}}$ & $0.48^{\mathrm{a}}$ & 0.07 & 0.000 & 0.000 & 0.000 \\
\hline$\beta$-Defensin 1 & 1.00 & 1.27 & 0.68 & 1.28 & 1.35 & 1.47 & 1.43 & 1.70 & 0.06 & 0.001 & 0.000 & 0.314 \\
\hline
\end{tabular}

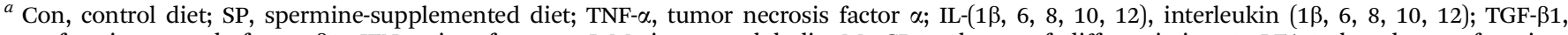
transforming growth factor $\beta 1$; IFN- $\gamma$, interferon $\gamma$; IgM, immunoglobulin M; CD8, cluster of differentiation 8; LFA-1, lymphocyte functionassociated antigen 1; CD18, integrin beta-2; iNOS, inducible nitric oxide synthase; LEAP2, liver-expressed antimicrobial peptide 2. SEM, standard error of the mean $(n=6$, number of replicates $) ;{ }^{\mathrm{a}-\mathrm{e}}$ Mean values with different superscripts in the same row are significantly different at $P<0.05$.

increased thereafter $(P<0.05)$. Spermine significantly reduced caspase-3 level (SP-9 d vs. Con-9 d).

\section{Discussion}

\section{Effect of spermine and its duration extension on hepatic amino acid transporters gene expression}

Spermine is essential for cell growth and proliferation. In this study, spermine significantly increased the weight of livers in weaning piglets, which indicated that spermine could improve the growth of liver. In addition, spermine is involved in amino acid absorption. ${ }^{18}$ The absorption of amino acids depends on amino acid transport, which primarily depends on specific amino acid transporters, including the SLC family. ${ }^{19}$ SLC1A1 regulates the cellular uptake of glutamate by transporting one $\mathrm{H}^{+}$and three $\mathrm{Na}^{+}$with the counter-transport of one $\mathrm{K}^{+}{ }^{19}$ Spermine increased the mRNA level of SLC1A1, indicating that spermine may promote glutamate transport in the liver. These results were consistent with a previous finding that spermine increased the mRNA level of SLC1A1 in the thymus and the spleen. ${ }^{2}$ SLC15A1 modulated the uptake of oligopeptide into intestinal and renal epithelial cells. ${ }^{20}$ Spermine supplementation increased the mRNA levels of SLC15A1. These results were consistent with our previous finding that spermine improved the mRNA levels of SLC15A1 in the spleen and the thymus. ${ }^{2}$ Therefore, spermine may improve liver growth by increasing the oligopeptide in the liver. SLC7A7 and SLC7A9 are subgroups of the SLC7 family that function as selective transport neutral amino acids (e.g., alanine, serine, and cysteine), aromatic amino acids (e.g., tyrosine, phenylalanine, and tryptophan) and negatively charged amino acids. ${ }^{21}$ Spermine increased the mRNA levels of SLC7A7 and SLC7A9 in the liver. Consistent with these results, spermine also increased the mRNA levels of SLC7A7 and SLC7A9 in the spleen of pigs. ${ }^{2}$ These data suggested that spermine may promote the transport of neutral, aromatic, and negatively charged amino acids. Overall, spermine supplementation improved the mRNA levels of amino acid transporters.

Table 4 Effect of spermine supplementation on TNF- $\alpha$, IL-1 $\beta$ and caspase 3 levels in the liver of piglets ${ }^{a}$

\begin{tabular}{|c|c|c|c|c|c|c|c|c|c|c|c|c|}
\hline \multirow[b]{3}{*}{ Parameters } & \multicolumn{8}{|c|}{ Treatment time } & \multirow[b]{3}{*}{ SEM } & \multirow{2}{*}{\multicolumn{3}{|c|}{$p$-Value }} \\
\hline & \multicolumn{2}{|l|}{$7 \mathrm{~h}$} & \multicolumn{2}{|l|}{$3 \mathrm{~d}$} & \multicolumn{2}{|l|}{$6 \mathrm{~d}$} & \multicolumn{2}{|l|}{$9 \mathrm{~d}$} & & & & \\
\hline & Con & SP & Con & SP & Con & SP & Con & SP & & SP & Time & $\mathrm{SP} \times$ time \\
\hline TNF- $\alpha\left(\mathrm{ng} \mathrm{g}^{-1}\right.$ tissue $)$ & 13.71 & 12.90 & 14.85 & 10.26 & 15.11 & 10.13 & 13.81 & 9.85 & 0.50 & 0.000 & 0.444 & 0.113 \\
\hline IL-1 $\beta$ (ng $\mathrm{g}^{-1}$ tissue) & 5.65 & 4.88 & 4.86 & 3.53 & 3.89 & 3.43 & 4.55 & 3.37 & 0.17 & 0.000 & 0.000 & 0.172 \\
\hline Caspase 3 & $2.90^{\mathrm{ab}}$ & $2.64^{\mathrm{a}}$ & $3.24^{\mathrm{abc}}$ & $2.72^{\mathrm{a}}$ & $3.50^{\mathrm{bc}}$ & $2.94^{\mathrm{ab}}$ & $5.52^{\mathrm{d}}$ & $3.76^{\mathrm{c}}$ & 0.19 & 0.000 & 0.000 & 0.016 \\
\hline
\end{tabular}

${ }^{a}$ Con, control diet; SP, spermine-supplemented diet; TNF- $\alpha$, tumor necrosis factor $\alpha$; IL-1 $\beta$, interleukin $1 \beta$. SEM, standard error of the mean $(n=3$, number of replicates); ${ }^{\text {a-e }}$ mean values with different superscripts in the same row are significantly different at $P<0.05$. 

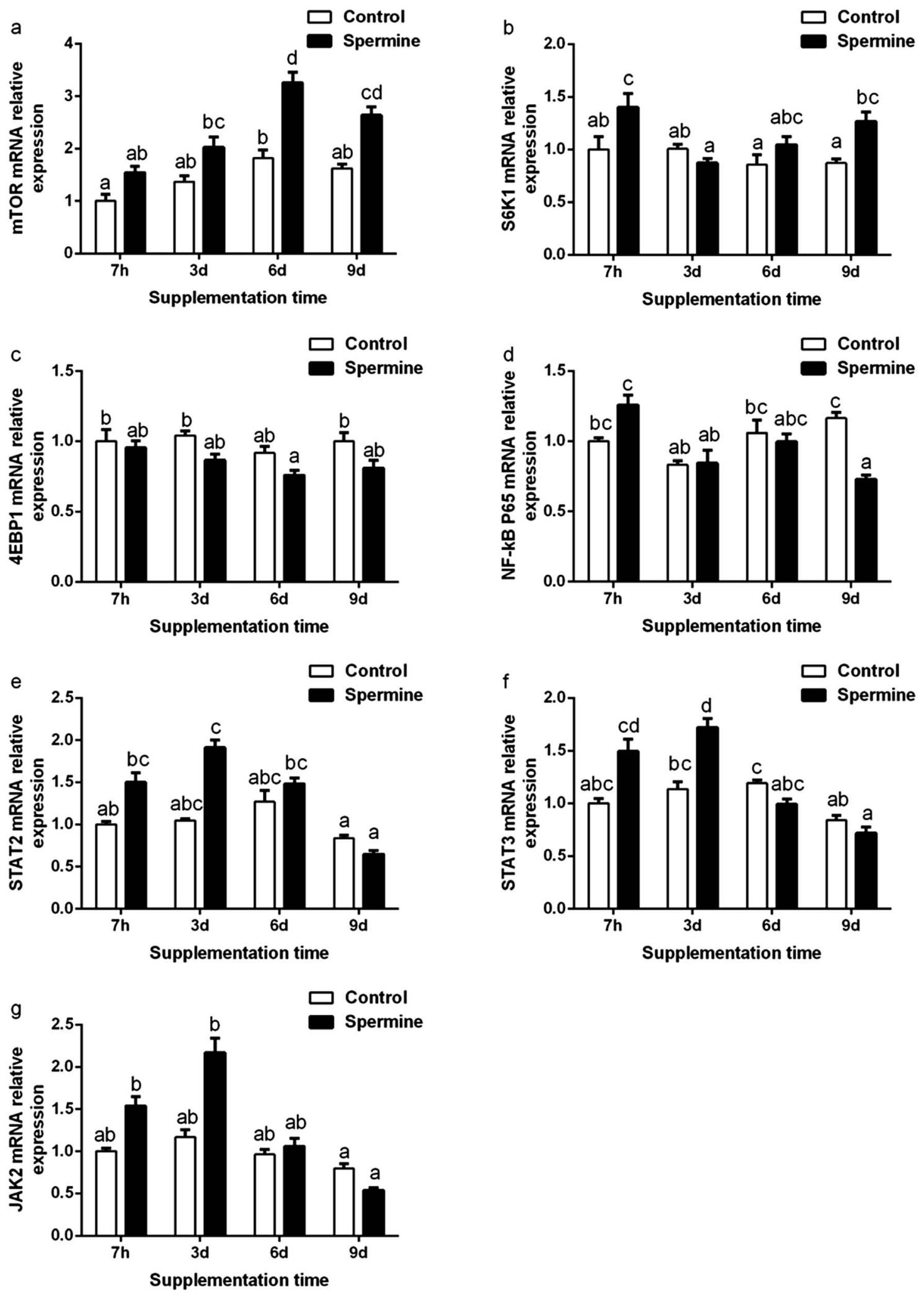

Fig. 1 Effect of spermine on the gene expression of immune-related genes. Pigs fed with spermine (spermine groups) or saline (control groups) for 7 hours, 3 days, 6 days and 9 days, respectively. The relative mRNA expression levels of mTOR (a), S6K1 (b), 4EBP1 (c), NF- KB P65 (d), STAT2 (e), STAT3 $(\mathrm{f})$ and JAK2 $(\mathrm{g})$ in the liver of piglets. The values are the means \pm standard error of the mean $(n=6)$. The different superscript letters $(a, b, c$, d) above the bars show significant differences at $P<0.05$. mTOR, mammalian target of rapamycin; S6K1, ribosomal protein S6 kinase 1; 4EBP1, eukaryotic IF4E-binding protein 1; NF- $\mathrm{B}$ P65, nuclear factor-kappa B P65; JAK2, Janus kinase 2; STAT3, signal transducer and activator of transcription 3; STAT2, signal transducer and activator of transcription 2. 
Table 5 Effect of spermine supplementation on the tight junction proteins mRNA levels in the liver of piglets ${ }^{a}$

\begin{tabular}{|c|c|c|c|c|c|c|c|c|c|c|c|c|}
\hline Parameters & \multicolumn{8}{|c|}{ Treatment time } & SEM & \multicolumn{3}{|c|}{$p$-Value } \\
\hline ZO-1 & $1.00^{\mathrm{c}}$ & $1.16^{\mathrm{cd}}$ & $0.83^{\mathrm{bc}}$ & $1.38^{\mathrm{d}}$ & $1.12^{\mathrm{cd}}$ & $1.16^{\mathrm{cd}}$ & $0.65^{\mathrm{ab}}$ & $0.49^{\mathrm{a}}$ & 0.05 & 0.006 & 0.000 & 0.000 \\
\hline $\mathrm{ZO}-2$ & $1.00^{\mathrm{c}}$ & $1.12^{\mathrm{c}}$ & $0.88^{\mathrm{bc}}$ & $1.11^{\mathrm{c}}$ & $1.12^{\mathrm{c}}$ & $1.11^{\mathrm{c}}$ & $0.75^{\mathrm{ab}}$ & $0.51^{\mathrm{a}}$ & 0.03 & 0.506 & 0.000 & 0.001 \\
\hline Claudin-2 & $1.00^{\mathrm{ab}}$ & $1.61^{\mathrm{c}}$ & $1.27^{\mathrm{b}}$ & $0.96^{\mathrm{ab}}$ & $1.23^{\mathrm{b}}$ & $1.85^{\mathrm{c}}$ & $1.02^{\mathrm{ab}}$ & $0.89^{\mathrm{a}}$ & 0.05 & 0.000 & 0.000 & 0.000 \\
\hline Claudin-3 & $1.00^{\mathrm{ab}}$ & $1.43^{\mathrm{abc}}$ & $1.46^{\mathrm{bc}}$ & $1.46^{\mathrm{bc}}$ & $1.55^{\mathrm{bc}}$ & $1.68^{\mathrm{c}}$ & $0.95^{\mathrm{a}}$ & $0.83^{\mathrm{a}}$ & 0.05 & 0.026 & 0.000 & 0.001 \\
\hline Claudin-14 & 1.00 & 2.28 & 1.98 & 1.98 & 6.05 & 6.11 & 4.25 & 4.25 & 0.29 & 0.126 & 0.000 & 0.108 \\
\hline Claudin-15 & $1.00^{\mathrm{b}}$ & $1.41^{\mathrm{d}}$ & $1.35^{\mathrm{d}}$ & $1.43^{\mathrm{d}}$ & $1.28^{\mathrm{cd}}$ & $1.19^{\mathrm{bcd}}$ & $1.03^{\mathrm{bc}}$ & $0.54^{\mathrm{a}}$ & 0.04 & 0.608 & 0.000 & 0.000 \\
\hline Claudin-16 & $1.00^{\mathrm{b}}$ & $1.45^{\mathrm{c}}$ & $0.54^{\mathrm{a}}$ & $0.88^{\mathrm{b}}$ & $0.59^{\mathrm{a}}$ & $1.01^{\mathrm{b}}$ & $0.44^{\mathrm{a}}$ & $0.39^{\mathrm{a}}$ & 0.05 & 0.000 & 0.000 & 0.001 \\
\hline MLCK & $1.00^{\mathrm{ab}}$ & $2.22^{\mathrm{b}}$ & $1.55^{\mathrm{b}}$ & $0.63^{\mathrm{a}}$ & $1.54^{\mathrm{ab}}$ & $1.01^{\mathrm{ab}}$ & $1.21^{\mathrm{ab}}$ & $0.52^{\mathrm{a}}$ & 0.08 & 0.010 & 0.000 & 0.000 \\
\hline
\end{tabular}

${ }^{a}$ Con, control diet; SP, spermine-supplemented diet; ZO-(1, 2), zonula occludens (1, 2); MLCK, myosin light chain kinase. SEM, standard error of the mean $\left(n=6\right.$, number of replicates). ${ }^{\text {a-d }}$ Mean in the same row with different superscripts are significantly different at $P<0.05$.

Effect of spermine and its duration extension on the immune status

A previous study posited that polyamine controlled the innate immune response in the mouse central nervous system during microbial challenges. ${ }^{22}$ The innate immune system is composed of the humoral and cellular immune systems. Antimicrobial peptides (e.g., liver-expressed antimicrobial peptide 2 (LEAP2), hepcidin, and $\beta$-defensin 1 ) and IgM are the components of the humoral immune system that are involved in antimicrobial action. $^{3}$ As shown in Table 3, spermine supplementation
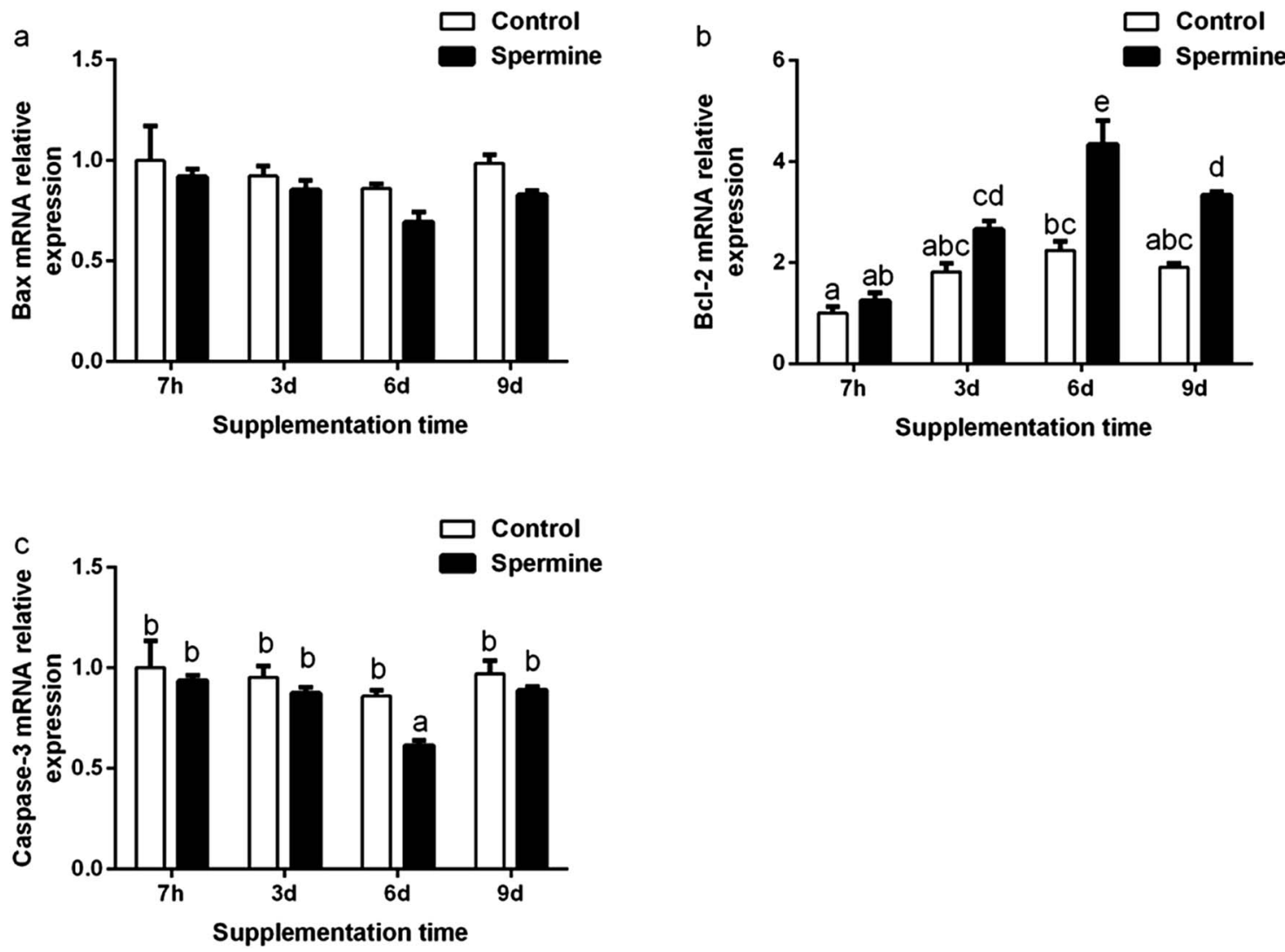

Fig. 2 Effect of spermine on the gene expression of apoptosis-related genes. Pigs fed with spermine (spermine groups) or saline (control groups) for 7 hours, 3 days, 6 days and 9 days, respectively. The relative mRNA levels of Bax (a), Bcl-2 (b) and caspase-3 (c) in the liver of piglets. The values are the means \pm standard error of the mean $(n=6)$. The different superscript letters $(a, b, c, d, e)$ above the bars show significant differences at $P<$ 0.05. Bax and $\mathrm{Bcl}-2$, apoptosis related factor. 
significantly increased the mRNA levels of IgM, LEAP2, hepcidin and $\beta$-defensin 1 in the liver. These results agreed with our previous finding that spermine increased the mRNA level of IgM in the thymus and spleen of pigs. ${ }^{6}$ Moreover, consistent with our results, dietary L-arginine significantly increased the mRNA levels of $\beta$-defensin 1 in the tongue of pigs and hepcidin in fish. ${ }^{4,23}$ These increased humoral components indicated that spermine improved the humoral immunity. The cellular immune system includes lymphocytes, which are responsible for innate immunity. ${ }^{3}$ CD8 is the maker of T lymphocytes. ${ }^{24}$ LFA1 and CD18 are the adhesion molecules that can modulate leukocytes to adhere and migrate to inflammatory sites. ${ }^{25}$ In the current study, spermine significantly increased the mRNA levels of CD8 and CD18 in the liver (Table 3). Correlation analysis revealed that the mRNA level of IgM was positively related to the mRNA level of CD8 $\left(r=+0.750, P<0.05^{*}\right)$, suggesting that the increased IgM mRNA level may be related to the increased CD8 mRNA level. These results suggested that spermine improved the cellular immunity in the liver, and that spermine supplementation could increase the innate immunity.

Inflammation mediated by inflammatory cytokines (pro- and anti-inflammatory cytokines) is a critical element in the response of the innate immune system to various challenges. ${ }^{7}$ Pro-inflammatory cytokines, including tumor necrosis factor $\alpha$ (TNF- $\alpha)$, IL-1 $\beta$, IL-6, IL-8, IL-12, and IFN- $\gamma$, up-regulate inflammatory reactions, whereas anti-inflammatory cytokines, such as IL-10 and transforming growth factor $\beta 1$ (TGF- $\beta 1$ ), inhibit that reaction. ${ }^{26}$ As shown in Table 3, spermine supplementation significantly reduced the mRNA levels of TNF- $\alpha$ and IL-8 but increased the mRNA level of TGF- $\beta 1$. Spermine also decreased TNF- $\alpha$ and IL-1 $\beta$ levels in the liver. This result agreed with the ELISA results (with the reduction of TNF- $\alpha$ ) on the serum in our previous study. ${ }^{6}$ Moreover, this result was consistent with our previous finding that spermine decreased the mRNA levels of TNF- $\alpha$ and IL- 8 but increased that of TGF- $\beta 1$ in the spleen of pigs. ${ }^{6}$ In addition, our previous study revealed that spermine reduced the mRNA levels of IL-1 $\beta$, IL-6, IL-12, and IFN- $\gamma$ and increased that of IL-10 in the spleen, whereas no difference was detected in the mRNA levels of these cytokines in the liver. ${ }^{6}$ The discrepancy in the effect may be due to the tissue differences in the organs, and this issue requires further investigation. ${ }^{6}$ Moreover, compared with other spermine groups, the IL- 8 and IFN- $\gamma$ mRNA levels were lower in the 9 $\mathrm{d}$ spermine group, and the TGF- $\beta 1$ mRNA level was higher in the $3 \mathrm{~d}$ spermine group, suggesting that the duration extension of spermine supplementation also affected the inflammatory response. These results implied that spermine could inhibit the inflammation by reducing the gene expression of proinflammatory cytokines and increasing that of antiinflammatory cytokines. The production of cytokines is regulated by nitric oxide (NO), which is mainly produced by inducible nitric oxide synthase (iNOS). ${ }^{27}$ Spermine significantly decreased the iNOS mRNA level in the liver (Table 3). This result was consistent with our previous study on the spleen of pigs. ${ }^{6}$ Correlation analysis revealed that the IgM mRNA level was negatively associated with the iNOS mRNA level $(r=-0.851, P<$
$0.01^{* *}$ ), suggesting that the increased IgM mRNA level may be attributed to decreased iNOS mRNA level.

Overall, spermine supplementation increased the innate immunity and regulated the gene expression of inflammatory cytokines in the liver. The immune status was modulated by several pathways, and the mTOR pathway is one of the signaling pathway molecules. ${ }^{6}$ Therefore, the succeeding analysis was conducted to investigate whether spermine and its duration extension affected mTOR.

\section{Effect of spermine and its duration extension on immune- related signaling molecules}

mTOR is considered the critical regulator of immune function. ${ }^{28}$ Ribosomal protein S6 kinase 1 (S6K1) and eukaryotic IF4Ebinding protein 1 (4EBP1) are the downstream signaling molecules of mTOR. The transcription of mTOR could activate the S6K1 gene expression and suppress the 4EBP1 gene expression. ${ }^{29}$ As presented in Fig. 1, spermine significantly upregulated the mTOR mRNA level and increased the S6K1 mRNA level in the liver. These results were consistent with a previous finding that spermine up-regulated mTOR and S6K1 in the thymus and the spleen. ${ }^{6}$ Correlation analysis revealed that the IL-8 mRNA level was negatively associated with mTOR mRNA level $\left(r=-0.738, P<0.05^{*}\right)$, implying that the decreased IL-8 mRNA level may be due to the increased mTOR mRNA level. When the spermine supplementation was extended, the mTOR mRNA level was gradually increased in the $6 \mathrm{~d}$ spermine group but was decreased in the $9 \mathrm{~d}$ spermine group. This result suggested that the duration extension of spermine affected the mTOR transcription.

A previous study revealed that the inhibition of mTOR promoted the production of pro-inflammatory cytokines through the NF- $\kappa \mathrm{B}$ but suppressed the production of antiinflammatory cytokines (IL-10) via STAT3. ${ }^{28}$ NF-кB P65 belongs to the NF- $\kappa \mathrm{B}$ family. The JAK-STAT pathway (including STAT2, STAT3, and JAK2) is a classical signal transduction pathway for cytokines. ${ }^{30}$ As shown in Fig. 1, spermine downregulated the NF- $\mathrm{B}$ P65 mRNA level but up-regulated the STAT3 mRNA level in the liver. This result was consistent with our previous finding that spermine reduced the NF- $\kappa$ B P65 and STAT3 mRNA levels in the thymus and the spleen. ${ }^{6}$ Correlation analysis revealed that the anti-inflammatory TGF- $\beta 1$ mRNA level was positively related to the STAT3 mRNA level $(r=+0.942, P<$ $\left.0.01^{* *}\right)$, suggesting that the increased TGF- $\beta 1$ mRNA level may be due to the increased STAT3 mRNA level. When the spermine supplementation was extended, the lowest NF-кB P65 mRNA level was observed in the $9 \mathrm{~d}$ spermine supplementation group, and the highest STAT3 mRNA level was detected in the 3 d spermine supplementation group.

In general, these results indicated that spermine regulated the gene expression of inflammatory cytokines by regulating the signaling pathway molecules. Spermine increased the mTOR gene transcription by regulating the gene expression of S6K1, NF-кB P65, and STAT3, and extending the spermine duration also affected the signaling molecules. Immunity depends on structural integrity, which in turn depends on the tight junction 
barrier of immune organs. ${ }^{8}$ Thus, the effect of spermine on the barrier function of the liver was investigated.

\section{Effect of spermine and its duration extension on barrier function}

The tight junction is important for structural integrity. ${ }^{9}$ Claudins plays a key role in tight junctions by regulating the permeability of the paracellular barrier. ${ }^{31}$ The ZO protein family includes ZO-1 and ZO-2, which directly link claudins to actin cytoskeleton and regulate the tight junction assembly. ${ }^{32}$ Occludin is the transmembrane protein associated with tight junctions in a regulatory capacity. ${ }^{31} \mathrm{~A}$ previous study reported that the barrier function was improved by the up-regulation of claudin-1, claudin-2, claudin-16, ZO-1, and occludin, and by the down-regulation of claudin- $-15 .^{33}$ As shown in Table 5, spermine supplementation increased the mRNA levels of claudin-1, claudin-2, claudin-16, ZO-1 and occludin in the liver. Consistent with our results, polyamine depletion decreased the protein levels of claudin-2, ZO-1, and occludin in IEC-6 cells. ${ }^{12}$ These results indicated that spermine supplementation improved the barrier function in the liver. The up-regulation of tight junction proteins may be due to MLCK. A previous study reported that the down-regulation of MLCK increased the tight junction protein levels. ${ }^{33}$ Spermine decreased the MLCK mRNA level in the liver. In general, spermine supplementation improved the physical barrier function, and this effect probably partly be contributed to the reduced MLCK level. Structural integrity depends on the cellular membrane, which could be destructed by cell apoptosis. ${ }^{34}$ Therefore, we investigated whether spermine inhibited apoptosis in the liver.

\section{Effect of spermine and its duration extension on apoptosis}

Apoptosis is critical for normal development and tissue homeostasis in the body. The Bcl-2 protein family and caspases play crucial roles in apoptosis. The Bcl-2 protein family includes the anti-apoptotic protein Bcl-2 and the pro-apoptotic protein Bax. ${ }^{35}$ Bcl-2 inhibits the mitochondrial apoptotic pathway, whereas Bax activates it. ${ }^{35}$ Caspases, such as caspase-3, could trigger the apoptotic process. ${ }^{35}$ A previous study reported that polyamine depletion increased the protein expression levels of $\mathrm{Bcl}-2$ but decreased Bax translocation and caspase-3 activity. ${ }^{36}$ As shown in Fig. 2, spermine supplementation increased the mRNA level of Bcl2 but decreased that of caspase- 3 and Bax (main effect). Spermine also decreased caspase-3 level in the liver. Our results were consistent with previous findings that spermine supplementation increased the transcription of Bcl-2 but decreased that of Bax and caspase-3 in the thymus and spleen of piglets. ${ }^{2}$ Correlation analysis revealed that the caspase- 3 mRNA level was positively related to the Bax mRNA level $\left(r=0.951, P<0.01^{* *}\right)$ but negatively associated with the Bcl-2 mRNA level $\left(r=-0.880, P<0.01^{* *}\right)$, suggesting that the decreased caspase-3 mRNA level may be due to the decreased Bax mRNA level and the increased Bcl-2 mRNA level. Moreover, a high polyamine concentration could possibly induce apoptosis, whereas polyamine depletion could prevent apoptosis. ${ }^{37}$ These results suggested that $0.4 \mathrm{mmol} \mathrm{kg}^{-1}$ of body weight of spermine inhibited the apoptosis in the liver of piglets.
In conclusion, our results indicated that spermine supplementation may regulate amino acid transport and enhance barrier function, and can improve immune status and inhibit the apoptosis in the liver of piglets.

\section{Conflicts of interest}

The authors declare no conflicts of interests.

\section{Acknowledgements}

The authors would like to thank the members of our team and the laboratory for their industrious assistance in this study. This study was supported by Specific Research Supporting Program for Discipline Construction in Sichuan Agricultural University (to G. Liu, No: 03570126).

\section{References}

1 E. Pegg, The function of spermine, IUBMB Life, 2014, 66, 818.

2 W. Cao, X. Wu, G. Jia, H. Zhao, X. Chen, C. Wu, J. Cai, J. Wang and G. Liu, Effects of dietary spermine supplementation on cell cycle, apoptosis, and amino acid transporters of the thymus and spleen in piglets, AsianAustralas. J. Anim. Sci., 2018, 31, 1325-1335.

3 B. Beutler, Innate immunity: an overview, Mol. Immunol., 2004, 40, 845-859.

4 X. Mao, S. Qi, B. Yu, Z. Huang, H. Chen, Q. Mao, G. Han and D. Chen, Dietary 1 - arginine supplementation enhances porcine $\beta$-defensins gene expression in some tissues of weaned pigs, Livest Sci., 2012, 148, 103-108.

5 B. Tan, X. G. Li, X. Kong, R. Huang, Z. Ruan, K. Yao, Z. Deng, M. Xie, I. Shinzato, Y. Yin and G. Wu, Dietary L-arginine supplementation enhances the immune status in earlyweaned piglets, Amino Acids, 2009, 37, 323-331.

6 W. Cao, X. Wu, G. Jia, H. Zhao, X. Chen, C. Wu, J. Tang, J. Wang, J. Cai and G. Liu, New insights into the role of dietary spermine on inflammation, immune function and related-signalling molecules in the thymus and spleen of piglets, Arch. Anim. Nutr., 2017, 71, 175-191.

7 J. Han and R. J. Ulevitch, Limiting inflammatory responses during activation of innate immunity, Nat. Immunol., 2005, 6, 1198-1205.

8 D. P. Berger, D. Naniche, M. T. Crowley, P. A. Koni, R. A. Flavell and M. B. Oldstone, Lymphotoxin-betadeficient mice show defective antiviral immunity, Virology, 1999, 260, 136-147.

9 E. E. Schneeberger and R. D. Lynch, The tight junction: a multifunctional complex, Am. J. Physiol.: Cell Physiol., 2004, 286, C1213-C1228.

10 S. Beutheu, I. Ghouzali, L. Galas, P. Dechelotte and M. Coeffier, Glutamine and arginine improve permeability and tight junction protein expression in methotrexatetreated Caco-2 cells, Clin. Nutr., 2013, 32, 863-869.

11 B. Wang, L. Feng, W. D. Jiang, P. Wu, S. Y. Kuang, J. Jiang, L. Tang, W. N. Tang, Y. A. Zhang, Y. Liu and X. Q. Zhou, 
Copper-induced tight junction mRNA expression changes, apoptosis and antioxidant responses via NF-kappaB, TOR and Nrf2 signaling molecules in the gills of fish: preventive role of arginine, Aquat. Toxicol., 2015, 158, 125-137.

12 X. Guo, J. N. Rao, L. Liu, T. Zou, K. M. Keledjian, D. Boneva, B. S. Marasa and J. Y. Wang, Polyamines are necessary for synthesis and stability of occludin protein in intestinal epithelial cells, Am. J. Physiol.: Gastrointest. Liver Physiol., 2005, 288, G1159-G1169.

13 H. J. Xu, W. D. Jiang, L. Feng, Y. Liu, P. Wu, J. Jiang, S. Y. Kuang, L. Tang, W. N. Tang, Y. A. Zhang and X. Q. Zhou, Dietary vitamin $\mathrm{C}$ deficiency depresses the growth, head kidney and spleen immunity and structural integrity by regulating NF-kappaB, TOR, Nrf2, apoptosis and MLCK signaling in young grass carp (Ctenopharyngodon idella), Fish Shellfish Immunol., 2016, 52, 111-138.

14 T. Fang, J. Zheng, W. Cao, G. Jia, H. Zhao, X. Chen, J. Cai, J. Wang and G. Liu, Effects of spermine on the antioxidant status and gene expression of antioxidant-related signaling molecules in the liver and longissimus dorsi of piglets, Animal, 2018, 12, 1208-1216.

15 X. Wu, W. Cao, G. Jia, H. Zhao, X. Chen, C. Wu, J. Tang, J. Wang and G. Liu, New insights into the role of spermine in enhancing the antioxidant capacity of rat spleen and liver under oxidative stress, Animal Nutrition, 2016, 3, 85-90.

16 T. Fang, G. Liu, W. Cao, X. Wu, G. Jia, H. Zhao, X. Chen, C. $\mathrm{Wu}$ and J. Wang, Spermine: new insights into the intestinal development and serum antioxidant status of suckling piglets, RSC Adv., 2016, 6, 31323-31335.

17 Z. B. Cheng, D. F. Li, J. J. Xing, X. Y. Guo and Z. J. Li, Oral administration of spermine advances intestinal maturation in sucking piglets, Anim. Sci., 2007, 82, 621-626.

18 G. Liu, T. Yan, T. Fang, G. Jia, X. Chen, H. Zhao, J. Wang and C. $\mathrm{Wu}$, Nutrimetabolomic analysis provides new insights into spermine-induced ileum-system alterations for suckling rats, $R S C A d v ., 2015$, 5, 48769-48778.

19 Y. Kanai, B. Clemencon, A. Simonin, M. Leuenberger, M. Lochner, M. Weisstanner and M. A. Hediger, The SLC1 high-affinity glutamate and neutral amino acid transporter family, Mol. Aspects Med., 2013, 34, 108-120.

$20 \mathrm{H}$. Daniel and G. Kottra, The proton oligopeptide cotransporter family SLC15 in physiology and pharmacology, Pflügers Arch., 2004, 447, 610-618.

21 F. Verrey, E. I. Closs, C. A. Wagner, M. Palacin, H. Endou and Y. Kanai, CATs and HATs: the SLC7 family of amino acid transporters, Pflügers Arch., 2004, 447, 532-542.

22 D. Soulet and S. Rivest, Polyamines play a critical role in the control of the innate immune response in the mouse central nervous system, J. Cell Biol., 2003, 162, 257-268.

23 B. Costas, L. E. Conceicao, J. Dias, B. Novoa, A. Figueras and A. Afonso, Dietary arginine and repeated handling increase disease resistance and modulate innate immune mechanisms of Senegalese sole (Solea senegalensis Kaup, 1858), Fish Shellfish Immunol., 2011, 31, 838-847.
24 C. M. Galdeano and G. Perdigon, The probiotic bacterium Lactobacillus casei induces activation of the gut mucosal immune system through innate immunity, Clin. Vaccine Immunol., 2006, 13, 219-226.

25 S. R. Yan, K. Sapru and A. C. Issekutz, The CD11/CD18 (beta2) integrins modulate neutrophil caspase activation and survival following TNF-alpha or endotoxin induced transendothelial migration, Immunol. Cell Biol., 2004, 82, 435-446.

26 A. H. Sprague and R. A. Khalil, Inflammatory cytokines in vascular dysfunction and vascular disease, Biochem. Pharmacol., 2009, 78, 539-552.

27 Y. Kobayashi, The regulatory role of nitric oxide in proinflammatory cytokine expression during the induction and resolution of inflammation, J. Leukocyte Biol., 2010, 88, 1157-1162.

28 T. Weichhart, G. Costantino, M. Poglitsch, M. Rosner, M. Zeyda, K. M. Stuhlmeier, T. Kolbe, T. M. Stulnig, W. H. HÖRl, M. Hengstschläger, M. Müller and M. D. Säemann, The TSC-mTOR signaling pathway regulates the innate inflammatory response, Immunity, 2008, 29, 565-577.

29 D. D. Sarbassov, S. M. Ali and D. M. Sabatini, Growing roles for the mTOR pathway, Curr. Opin. Cell Biol., 2005, 17, 596603.

30 B. Lei, H. Zhang and L. S. Chan, The involvement of the JAKSTAT signaling pathway in chronic inflammatory skin disease atopic dermatitis, JAK-STAT, 2013, 2, e24137.

31 M. K. Findley and M. Koval, Regulation and roles for claudinfamily tight junction proteins, IUBMB Life, 2009, 61, 431437.

32 A. S. Fanning and J. M. Anderson, Zonula occludens-1 and -2 are cytosolic scaffolds that regulate the assembly of cellular junctions, Ann. N. Y. Acad. Sci., 2009, 1165, 113-120.

33 L. Li, L. Feng, W. D. Jiang, J. Jiang, P. Wu, J. Zhao, S. Y. Kuang, L. Tang, W. N. Tang, Y. A. Zhang, X. Q. Zhou and Y. Liu, Dietary pantothenic acid depressed the gill immune and physical barrier function via NF-kappaB, TOR, Nrf2, p38MAPK and MLCK signaling pathways in grass carp (Ctenopharyngodon idella), Fish Shellfish Immunol., 2015, 47, 500-510.

34 J. D. Schulzke, C. Bojarski, S. Zeissig, F. Heller, A. H. Gitter and M. Fromm, Disrupted barrier function through epithelial cell apoptosis, Ann. N. Y. Acad. Sci., 2006, 1072, 288-299.

35 V. S. Marsden and A. Strasser, Control of apoptosis in the immune system: Bcl-2, BH3-only proteins and more, Annu. Rev. Immunol., 2003, 21, 71-105.

36 Q. Yuan, R. M. Ray and L. R. Johnson, Polyamine depletion prevents camptothecin-induced apoptosis by inhibiting the release of cytochrome c, Am. J. Physiol.: Cell Physiol., 2002, 282, C1290-C1297.

37 N. Seiler and F. Raul, Polyamines and apoptosis, J. Cell. Mol. Med., 2005, 9, 623-642. 